\title{
AVALIAÇÃO E DEVOLUTIVA: ELEMENTOS INDISSOCIÁVEIS NO CONTEXTO DO ENSINO SUPERIOR A DISTÂNCIA
}

\author{
C. M. FIORAVANZO ${ }^{1}$, A. M. VIEIRA ${ }^{1}$ e J. A. C. S. CLARO ${ }^{2 *}$ \\ ${ }^{1}$ Universidade Metodista de São Paulo \\ ${ }^{2}$ Universidade Federal de São Paulo \\ albertoclaro@albertoclaro.pro.br*
}

Artigo submetido em junho/2014 e aceito em janeiro/2016

DOI: $10.15628 /$ holos.2016.2203

\section{RESUMO}

O EaD tem sido alvo de interesse de diversos pesquisadores com o intuito de oferecer alternativas e incremento nos processos de ensino, aprendizagem e extensão universitária. O presente estudo analisa a importância da devolutiva das atividades nesta modalidade de ensino. Relacionaram-se as formas de devolutivas com o modelo de superação bancária defendido por Paulo Freire. Chegou-se a algumas vertentes positivas em EaD que contribuem na abordagem da devolutiva e interação do conteúdo das avaliações. A estratégica metodológica foi um estudo de caso único. Seu protocolo consistiu na análise de amostra de 157 alunos do ensino a distância de uma instituição privada de ensino superior localizada no estado de São Paulo e que abrange todo o Brasil. $O$ instrumento de coleta de dados foi composto por 26 afirmativas relativas baseadas em quatro constructos aplicados: aulaatividade, prova integrada presencial, planejamento semanal e fórum de dúvidas. A análise confirmou a importância da devolutiva de acordo com a perspectiva do alunado. Possibilitou ainda, identificar a relação da importância da devolutiva com o modelo Democratização, Autonomia nos estudos e Relação professor-aluno menos hierarquizada.

PALAVRAS-CHAVE: Ensino a distância, Tecnologia, Avaliação, Devolutiva.

\section{EVALUATION AND FEEDBACK: INSEPARABLE ELEMENTS IN THE LONG-DISTANCE HIGHER EDUCATION SCENARIO}

\section{ABSTRACT}

Long-distance education (LDE) is one of the most important issues in the academic debate when it comes to discuss alternative ways of teaching, learning and university extension. Along with this matter, this article deals with the importance of feedback derived from academic activities of the above-mentioned way of teaching. Some models of feedback evaluation have been compared to the "bank education idea" criticized by brazilian researcher Paulo Freire. The research adopted a case study approach, with a 157 LDE students sample. The questionnaire has been developed with 4 assumptions based in the students point of view, taking to account the importance of feedback evaluation. As a result, some issues related to the student/teacher relationship have been identified, as well as democracy, autonomy and lower-level of hierarchy from teacher to student.

KEYWORDS: Long-distance education, Technology, Evaluation, Feedback 


\section{INTRODUÇÃO}

O mercado de trabalho tem exigido contínua capacitação profissional, e nesse contexto o ensino superior tornou-se um item básico de qualificação exigida na maioria das organizações. Mattos (1999) preconizou que grandes mudanças ocorreriam nas empresas e no emprego, como resultado do crescimento da Internet. Empresas e profissões desapareceriam e outras criadas, dizia ele. E a educação seria a segurança para não se perder nessas mudanças. No entanto, nem todos os indivíduos possuem condições financeiras e/ou geográficas para cursar o ensino superior presencial.

Nesse contexto, a modalidade do Ensino a Distância (EaD) surge e oferece uma alternativa de estudo que visa contemplar os indivíduos com tais restrições. O uso intensivo da tecnologia permite a aplicabilidade e o acompanhamento, monitorando o processo de ensino-aprendizagem, de forma muito abrangente (BENFATTI; STANO, 2010). Mas não foi sempre assim. Já houve preconceito e insegurança quanto a esta modalidade formativa, como atesta Segenreich (2006). E não só na educação formal, como também na educação corporativa (BRAUER; ALBERTIN, 2010), apesar de que as barreiras estão sendo vencidas e a aceitação está mais presente (TEZZA, 2012).

A Tecnologia da Informação e Comunicação (TIC) permite a conexão entre os envolvidos no processo: professores temáticos, alunos, professores auxilia res (tutores), monitores a distância e presentes nos polos de apoio presenciais. Porém, somente a possibilidade de frequentar o curso e fazer parte deste processo não basta, é necessário que haja efetivamente a interação entre os envolvidos e que o estudo contribua de forma significativa para a formação dos indivíduos. A avaliação tem um processo mais amplo do que propostas conservadoras, devendo, além de tudo, favorecer o desenvolvimento da capacidade do indivíduo (VEIGA, 2004).

Diante do exposto, a devolutiva apresentada nas avaliações e atividades desenvolvidas pelos alunos precisa ocorrer de forma a superar a concepção bancária, na qual o educador apenas 'deposita' informações aos educados, sem direito ao diálogo. Na superação, sugere trabalhar a educação como prática de liberdade, com a realidade inserida no contexto educativo, valorizando assim o diálogo (FREIRE, 1987).

Diante desse contexto, propõe-se uma análise crítica da avaliação em EaD, como ela vem sendo empregada nesta modalidade do ensino e como ocorre seu processo de devolução aos alunos por meio do estudo de caso realizado em uma Instituição de Ensino Superior (IES) privada.

Assim como é dito no estudo apresentado por Silva e Silva (2009), se trabalhar, sob a forma de pesquisa empírica, as questões avaliativas em EaD é fundamental para futuras práticas dessa modalidade de ensino e para o próprio tema 'avaliação'.

Definiu-se, como método, estudar uma IES privada que possui polos de EaD em todo o Brasil, utilizando protocolo com aplicação de questionários online, e as respostas analisadas de forma descritiva por se tratar de um estudo exploratório e inicial.

Este texto está estruturado da seguinte forma: primeiramente é realizada uma revisão teórica sobre a temática, secundariamente é apresentada a metodologia utilizada no estudo e a análise dos resultados, e, posteriormente, as considerações finais. 


\section{REVISÃO BIBLIOGRÁFICA}

A modalidade do Ensino a Distância (EaD) no Brasil está em processo de expansão. As Instituições de Ensino Superior (IES) procuram se adequar a esta 'revolução educacional'. Pesquisadores se debruçam sobre o tema, que ganha cada vez mais espaço nas pesquisas em ciências sociais e humanas. Cavalcanti Júnior e Ferraz (2013) investigaram os periódicos brasileiros de Administração (QUALISCAPES A2, B1 e B2), para compreender como a EaD tem sido estudada na área, de 2002 a 2011. Chegaram às seguintes constatações: havia uma forte predominância de trabalhos empíricos, que, por sua vez, estavam inseridos no paradigma funcionalista; há maior utilização da abordagem qualitativa, dentro da qual a estratégia de investigação preponderante é o estudo de caso; apuraram que a entrevista constitui-se na técnica de coleta de dados mais empregada. Ao total foram encontrados 22 artigos publicados.

O ensino a distância oferece não só uma alternativa de estudo que possibilita a oportunidade de pessoas que possuam restrições, sejam elas de caráter pessoal ou profissional, possam frequentar um curso superior, mas também uma alternativa de aperfeiçoar e complementar o currículo. Mas alguns fatores críticos de sucesso para cursos a distância precisam ser observados pelos gestores educacionais (LIMA et al., 2012). O uso das TICs na educação é uma delas.

Diante da velocidade do desenvolvimento tecnológico, usando-se novas tecnologias digitais e do progresso das telecomunicações, o ensino a distância está numa constante crescente (BRASIL, 2010), o que é ressaltado por Almeida et al. (2012). O avanço das tecnologias de informação e comunicação também resultou no desenvolvimento do ensino a distância (TAKAHASHI, 2000). 0 uso da tecnologia na educação se baseia em diversas ferramentas, mas principalmente nas multimídias. Uma obra que trata com profundidade sobre essa temática foi organizada por Souza, Moita e Carvalho (2011). Gomes (2013, p. 13) argumenta que "a presença das tecnologias atuais de informação e de comunicação no cotidiano educacional, tanto no ensino presencial quanto no a distância deve ser transformadora", e deve potencializar e pressupor "um outro paradigma educacional, que passa pela descentralização do currículo, do empoderamento dos alunos e da presença forte das comunidades de aprendizagem e das redes de relacionamento" (p. 13).

Tecnologia na modalidade do Ensino a Distância (EaD) é o fator fundamental e essencial para a aprendizagem, interatividade e desenvolvimento do aluno. Isto posto, a aceitação da tecnologia pelos envolvidos no processo é de caráter mandatória e não voluntária. O uso intenso das Ticos permite a aplicabilidade e monitoramento do processo de ensino-aprendizagem nesta modalidade (NOVAIS; FERNANDES, 2011). Inclusive a própria rotina e gestão que o curso nessa modalidade exige, resulta em aprendizagem para a própria organização de ensino (CARVALHO et al., 2010; SILVA; ROCHA, 2012; CLEMENTINO et al., 2012), bem como a preocupação com a inovação dos serviços em EaD, inserindo-se aí, os aspectos relativos à avaliação do aprendizado (TEIXEIRA; ISIDRO FILHO, 2012).

Para Rivard e Lapointe (2005), os indivíduos e grupos podem ter várias intenções de comportamentos quanto à percepção de uma mudança de tecnologia: adoção, neutralidade, apatia, resistência passiva, resistência ativa ou resistência agressiva. No entanto, no ensino a distância, se a intenção de usar a tecnologia não for uma característica presente no aluno, todo o processo e ensino-aprendizagem pode ser comprometido. Diante do exposto, os indivíduos que se predispõem a essa modalidade de ensino, precisam lidar com ferramentas tecnológicas, para 
obterem êxito no aprendizado e no cumprimento de suas atividades acadêmicas que são, em sua grande maioria, essencialmente virtuais.

São denominações Ambientes Virtuais de Aprendizagem (AVA), Ambientes de Aprendizagem Online, Sistemas Gerenciadores de Educação a Distância, Software de Aprendizagem Colaborativa, utilizadas para softwares desenvolvidos para o gerenciamento da aprendizagem via web. Este tipo de sistema implica na funcionalidade de software para comunicação mediada pelo computador e métodos de entrega de material de cursos online (SCHELEMMER; FAGUNDES, 2000; KLERING; SCHRÖEDER, 2011). Os estudos que investigam as estratégias de ensino e/ou aprendizagem em AVAs cresceu no período anterior a esta pesquisa (BELUCE; OLIVEIRA, 2012).

Analisando o modelo adotado pelas Instituições de Ensino Superior (IES), a Tecnologia da Informação e Comunicação (TIC) permite a conexão entre todos os envolvidos no processo: professores temáticos, alunos, professores auxiliares, monitores a distância e presentes nos polos de apoio presenciais. A interatividade pode ser manifestada em diversas ações, sendo elas comuns e coletivas como nos fóruns de dúvida e chats, ou por ações individuais por meio de mensagens aos professores, com intuito de eliminar possíveis dúvidas.

Nesse sentido o processo de avaliação do aprendizado virtual surge, inclusive como parte de uma avaliação maior no ensino superior no Brasil, como aponta Félix (2013). Para Quintana e Quintana (2012, p. 1) essa avaliação é integrada por uma parte virtual e outra presencial. “A postagem da tarefa torna-se um importante instrumento de comunicação (...), pois possibilita a troca de informações (...), além de servir como componente de avaliação e, por consequência, refletir no desenvolvimento do processo de ensino e aprendizagem". Eles analisarama forma de execução das tarefas virtuais dos alunos de um curso de graduação em Administração a distância e perceberam que "é fundamental que professores, tutores e coordenação dos cursos a distância prestem atenção às necessidades dos estudantes em relação ao tempo para execução das atividades, data apropriada para postagem e atendimento a dúvidas" (p. 1).

Alguns modelos de avaliação em EaD podem ser encontrados na teoria. Avisam Maluleque e Costa (2012), como exemplo, que em Moçambique há uma discrepância nas práticas de avaliação online relativamente ao que está regulamentado naquele país e ao que a literatura sugere. Isso pode denotar uma necessidade futura de estudos no Brasil para que se confirme se há esse fenômeno por aqui. Bertolin e De Marchi (2010) lembram a complexidade do tema avaliação em educação e sua importância nas abordagens e projetos de qualidade de instituições, cursos e disciplinas da educação superior. No âmbito da educação a distância (EaD), para os autores, a avaliação da qualidade da educação adquire uma relevância e complexidade ainda maiores em virtude das diferenças de espaço e tempo entre docente e discente, o que certamente impacta no processo de aprendizagem. Eles desenvolveram uma proposta de instrumento para avaliação de disciplinas semipresenciais da educação superior, que incorpora aspectos de auto validação, ao permitir o cotejamento entre os indicadores de resultados e aspectos de entradas e processo da disciplina, e entre a avaliação de um sujeito interessado e a auto avaliação de outros sujeitos envolvidos (BERTOLIN; DE MARCHI, 2010).

A necessidade dos professores aprenderem a planejar aulas, materiais de ensino, a dinâmica das aulas e formas de avaliaçãoé sugerida por Schroeder (2009), apesar de Freitas (2012, p. 9) afirmar que "professor não mais participa das etapas de planejamento e avaliação dos 
conteúdos, tornando-se um mero executor de programas e políticas elaboradas pela administração pública educacional". Os docentes também se preocupam com a questão da aprendizagem de seus alunos, independente do ambiente que estejam, mas com maior incidência em modalidades de interação a distância (SOUZA-SILVA; DAVEL, 2007).Os tutores estão inseridos no processo da mesma forma, como propõem Sawitzki et al. $(2012$, p. 1), pois "apesar de a tutoria preconizar flexibilidade, implica organizar e reservar tempo pessoal, a fim de realizar atividades a ela inerentes, por exemplo, avaliação de tarefas realizadas pelos alunos". Porém, Frota e Teodósio (2012) apontam que o trabalho docente tem sido cenário de uma "autonomia relativizada", ao analisarem os processos de sofrimento no trabalho de professores universitários em uma IES privada e as estratégias desenvolvidas para lidarem com essa realidade. Os resultados indicaram que, apesar de satisfeitos com a profissão (e com a IES), há o reconhecimento de que o aumento da carga de trabalho, precarização das condições de trabalho, mercantilização do ensino, aumento do número de IES, maior ênfase no resultado econômico e dificuldade do professor se manter atualizado são fontes relevantes de sofrimento no trabalho docente. Já Caldas et al. (2012), perceberam que não há diferença de satisfação entre docentes temáticos e auxiliares em EaD.

Empresas e gestores de pessoas também se preocupam com esse aspecto do uso da educação a distância. O objetivo de identificar as características das iniciativas de Educação a Distância, via internet, em grandes empresas privadas brasileiras, norteou a descrição das características dessas iniciativas por Ghedine et al. (2008), tais como a estrutura dos cursos, seus respectivos públicos-alvo, tecnologias empregadas, métodos para avaliação, entre outros aspectos.

Vieira e Santos (2005) afirmaram que a gestão estratégica do conhecimento aplicada ao campo da avaliação institucional constrói um sistema informático que permite mensurar a adequação de desempenho dos processos que compõem o Ensino a Distância, e basearam uma modelagem nas demandas de organizações públicas envolvidas na pesquisa e, também, no levantamento de requisitos junto às equipes multidisciplinares que trabalhavam com EaD em Instituições Federais de Ensino Superior. Ao final, perceberam que a identificação dos requisitos de informação dos agentes envolvidos permitiria a proposição de ferramenta de avaliação integrada e abrangente, que proporcionasse uma retroalimentação de informações confiáveis e eficientes.

As IES já utilizam a tecnologia para que os alunos vivenciem de forma prática a gestão em uma organização. Para tanto, incluem no conteúdo programático a inserção da disciplina Jogos de Empresa, como no caso da IES estudada aqui. Os princípios educacionais norteadores dos jogos de empresas são sustentados pela teoria da aprendizagem vivencial (KEYS; WOLFE, 1990; SAUAIA, 2008).

Apesar de conter algumas diferenças da realidade, os jogos de empresas computadorizados são simulações de processos decisórios dentro de contextos empresariais e podem ser considerados como método educacional, visto que os participantes, geralmente agrupados em equipes, analisam e estudam diversos problemas e situações do modelo empresarial, simulando ciclos sucessivos de decisões e de resultados (MARTINELLI,1987; SAUAIA, 2008).

Nos jogos de empresa, por meio de uma simulação com o auxílio de computadores, o aluno tem a possibilidade assumir a responsabilidade dentro de uma empresa e age tomando decisões para que os problemas encontrados diariamente no mercado de trabalho transformem em 
oportunidades, de forma que os negócios prosperem. Com este exercício, o aluno desenvolve sua capacidade e habilidade de decidir em uma organização. Isso graças à tecnologia. É o que Jeannot e Jolibert (2013) chamam de simulação orientada. Para Sauaia (2008), as simulações gerenciais podem ser definidas como um exercício de tomada de decisão, na forma de jogos que reproduzem de forma parcial e simplificada, uma situação que poderia fazer parte da realidade.

Apesar de pesquisas em avaliação de treinamentos a distância ainda serem incipientes (ZERBINI; ABBAD, 2009), em trabalho que avaliou um curso a distância mediado pela Internet e oferecido gratuitamente em nível nacional, Carvalho e Abbad (2006) perceberam que os indivíduos receberam mais favoravelmente os resultados e a aplicabilidade do curso, ligada à realidade do seu cotidiano.

Para Veiga (2004), a avaliação tem um processo mais amplo do que propostas conservadoras, deve, além de tudo, favorecer o desenvolvimento da capacidade do indivíduo e deve ser resultante de um processo coletivo de avaliação. Para tanto, diante dos adventos da tecnologia na avaliação no modelo EaD, não sendo possível o contato pessoal com o indivíduo, a fim de minimizar os impactos no processo de avaliação do aluno, foram estabelecidas algumas diretrizes para adequação do modelo a esta linha. O referencial de qualidade do EaD estabelecido pelo MEC (2007), em complemento às determinações específicas da Lei de Diretrizes e Bases da Educação, do Decreto 5.622, de 20 de dezembro de 2005, do Decreto 5.733, de junho de 2006 e das Portarias Normativas 1 e 2 de 11 de janeiro de 2007, segue a esta linha de pensamento (MEC, 2007). As avaliações, na modalidade de ensino a distância, devem promover um permanente acompanhamento dos estudantes para, assim, identificar possíveis dificuldades na aprendizagem e auxiliar o aluno durante o processo de ensino-aprendizagem. As avaliações finais são compostas por conjunto de avaliações a distância (virtuais) e avaliações presenciais, sendo estas últimas obrigatórias no processo.

Para que este conhecimento não seja apenas um repasse de informações, destaca-se a importância da devolutiva das avaliações e atividades desenvolvidas pelos alunos, tornando dessa forma, uma relação conjunta. Para Freire (1987), na concepção bancária, o conhecimento, o saber, é visto como uma doação do educador ao educando. A educação não é considerada como um processo de busca e troca de conhecimento entre o educador e o educando, ou seja, nessa concepção, o educador é o único que possui o conhecimento enquanto o educando está ali somente para receber conteúdos, estes recebem pacientemente, memorizam e repetem. "O educador faz 'comunicados' e depósitos que os educandos, meras incidências, recebem pacientemente, memorizam e repetem" (FREIRE, 1987, p.33).

Para que o ensino a distância não se confunda e, realmente, não se enquadre a esta forma de concepção bancária, é extremamente necessário o diálogo e interação com o aluno. Além das ferramentas, é de grande importância que o aluno receba o retorno de suas atividades, suas reflexões e, ainda assim, tenha a possibilidade de interagir novamente com manifestações de dúvida e/ou complementos sobre os assuntos.

Na superação da concepção, Freire (1987) sugere trabalhar a educação como prática de liberdade, onde a realidade é inserida no contexto educativo, valorizando assim o diálogo, a reflexão e a criatividade do educando. O diálogo é uma exigência existencial, é o grande incentivador de uma educação mais humanizada. O diálogo entre educador e o educando tem seu início na busca do conteúdo programático. Este não deve ser uma doação ou uma imposição e, 
sim, uma devolução "[...] organizada, sistematizada e acrescentada ao povo, daqueles elementos que este lhe entregou de forma desestruturada" (FREIRE, 1987, p.47).

Com a devolutiva das avaliações, os professores estão valorizando as atividades, reflexões, desenvolvidas pelo alunado, assim como Freire (1987) discorre sobre a superação da concepção bancária. No livro Pedagogia da Autonomia, Freire (1996) expõe que educar é como viver, o que exige uma consciência do inacabado, um movimento constante de busca. Para tanto, o processo da devolutiva aqui tratada, deve ser um ato constante e deve fazer parte do cotidiano destes alunos. Para Santos (2006), a avaliação ainda fica reduzida a dados quantitativos e a função formativa da avaliação não é empregada. Ainda que possa ser a realidade de muitas instituições, não se pode generalizar esta questão, sendo que algumas já empregam a avaliação formativa e constante, amenizando este contraponto. Não se deve esquecer de que, como afirma Demo (2003, p. 18), "os professores precisam entender que o centro do processo é constituído pelo aluno, não por ele, que é, aí, figura de orientação e avaliação".

Dado que a educação em ambientes virtuais refere-se a experiências de aprendizagem que utilizam recursos hiper midiáticos em ambientes apoiados por uma tecnologia de comunicação, o estudo de Laguardia et al. (2007) optou por enfocar tópicos relativos à avaliação de tecnologias de informação e de aprendizagem nesses ambientes, aprofundando a discussão no que tange aos métodos relevantes à avaliação, tanto dos ambientes virtuais de aprendizagem quanto da aprendizagem nesse meio.

Ao elaborar suas ideias a respeito do caráter da avaliação frente a uma concepção formativa, em um ambiente de $\mathrm{EaD}$, que valorizasse todos os tipos de interação, Rosa e Maltempi (2006) aliaram o construcionismo à avaliação formativa, visando ao aperfeiçoamento do processo de aprendizagem do aluno, em vez de buscar medir o que este aprendeu.

Em estudo que analisou e avaliou processos de aprendizagem num curso de graduação em Administração (EaD), numa IES pública, privilegiando a perspectiva construtivista e a avaliação do tipo formativa, os resultados revelaram certo paradoxo entre o nível intermediário do 'sentimento de comunidade' percebido pelos estudantes e o nível inferior, ou preliminar, da 'aprendizagem coletiva', constatado nas participações dos estudantes nos ambientes virtuais (MONDADORI; SCHRÖEDER; RUAS, 2008).

Rausch et al. (2012, p. 1) descreveram uma prática de avaliação formativa realizada na disciplina de matemática financeira com alunos de graduação, fundamentada no conceito de avaliação formativa e operacionalizado por meio de uma pesquisa-açãoe os resultados indicam que, "no caso analisado, o professor estabeleceu meios para concretizar o que a literatura descrita considera como relevante para transformação da avaliação em um processo de aprendizagem". Não é à toa que o EaD é a modalidade de ensino-aprendizagem mais apropriada para reduzir as distâncias e os isolamentos geográficos, psicossociais, econômicos e culturais, caracterizando assim uma nova revolução na democratização do conhecimento. Nesse sentido contribui com a prática da liberdade (LANDIM, 1997).

Um trabalho que apresentou a experiência brasileira na organização de metodologias e estratégias de avaliação de competências profissionais do auxiliar de enfermagem foi elaborado por Marques et al. (2007). Dentro da sua proposta metodológica de avaliação de competências profissionais na perspectiva crítico-emancipatória, foi desenvolvido um ambiente de teleeducação, com a criação de softwares, do homem virtual e do 'cyber tutor' de avaliação. Assim, os 
módulos de avaliação consideraram as competências nas dimensões do saber-saber, saber-fazer e saber-ser, baseados em perfil profissional das práticas hos pitalares e de unidades básicas de saúde do serviço público de saúde. O instrumento mostrou ser uma importante estratégia de otimização dos procedimentos de avaliação para uso em larga escala no Brasil, além de um instrumento importante para educação permanente.

Outro fator interessante é que nesta modalidade há um estreitamento na relação professor-aluno, por conta de existirem ferramentas que não possuem delimitações de forma tão clara quanto as diferenças entre eles ao utilizarem ferramentas comuns em ambas as partes, é notória a maior participação do indivíduo, pois há menor inibição, constrangimento por parte do alunado para interagir e expressar suas opiniões ao professor, e até mesmo aos colegas.

Uma investigação que entende Avaliação Participativa (AP) em seu acoplamento com Tecnologias da Informação e da Comunicação (TICS) mostrou como foram captadas (observação e mini estudos etnográficos), registradas (protocolos e estudos de caso) e analisadas (referenciais) as formas de avaliação que foram praticadas em cenários universitários, educação presencial e não presencial, EaD e em cenários de ações sociais e educação não formal, praticadas em periferias urbanas (LEITE et al., 2007).

Com base nas reflexões, chega-se a algumas vertentes positivas na modalidade EaD neste sentido e que contribuem para a questão da devolutiva e interação do conteúdo das avaliações, chamadas de vertentes DAR (Democratização, Autonomia nos estudos e Relação professor-aluno menos hierarquizada), conforme a Figura 1, abaixo:

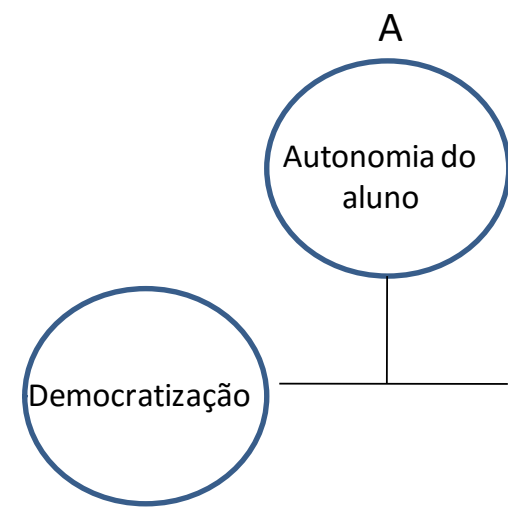

D

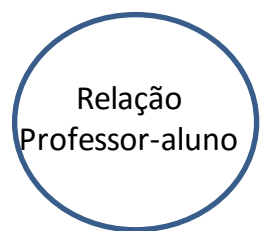

$\mathrm{R}$

Figura 1 - Modelo DAR

Fonte: Modelo elaborado pelos autores

Tem-se a seguinte explicação baseada na Figura 1:

a) A questão da democratização (D);

Democratiza o acesso à educação, por atender alunos que possuem diferentes posições geográficas e que muitas vezes residem em locais em que não há instituições de ensino, o que exige menos recursos financeiros.

b) Autonomia nos estudos (A); 
Proporciona a aprendizagem autônoma pelo fato de contar com experiência dos alunos sem afastá-los do seu local de trabalho. Há uma 'liberdade' de estudos, o que faz que ele seja responsável pela sua aprendizagem.

c) Relação professor-aluno menos hierarquizada ( $R$ );

Há uma quebra de paradigma na comunicação entre o professor e o aluno, que de fato, muitos alunos sentem-se intimidados diante de situações de questionamento no modelo presencial. Na modalidade EaD, o aluno tem acesso direto e constante com seu professor, de forma que poderá compartilhar suas dúvidas com os demais colegas ou poderá manter o contato particular com o professor, sem que haja nenhum tipo de inibição.

Por outro lado, observa-se também limitações nesse sentido:

a) Observar mudanças comportamentais do aluno, que são critérios importantes para uma avaliação mais qualitativa;

b) A distância geográfica obriga o estabelecimento de algumas regras, de forma mais inflexível, por não existir o contato pessoal;

A literatura trata da visão do discente sobre as práticas de avaliação em EaD. Nos resultados obtidos junto a alunos de ensino superior, Arieira et al. (2009) pedem atenção à forma com que os acadêmicos receberam e se inseriram na dinâmica do ensino online. A pesquisa demonstra que a maioria dos alunos mostrou-se satisfeita comos resultados alcançados e com as possibilidades que a plataforma de ensino a distância permite para a complementação do aprendizado e os aspectos relativos à avaliação. Porém, é necessário cautela. A pesquisa de Pedrosa e Mamede-Neves (2012) demonstra que os jovens que ingressaram pelo ProUni (Programa Universidade para Todos) na universidade particular onde o estudo foi feito acompanharam os avanços tecnológicos de forma diferente da que é apontada pelo senso comum, sendo que "essas colocações confirmavam que não basta aos jovens ingressar na universidade; também é fundamental dar-lhes apoio e condições para que nela permaneçam com proveito e tenham, todos, uma trajetória universitária em pé de igualdade com os demais alunos" (PEDROSA; MAMEDE-NEVES, 2012, p. 144).

Oliveira (2010, p. 1) mostra as amplas possibilidades da avaliação multidimensional da aprendizagem em ambientes colaborativos online, a qual, para ele, "oportuniza o ajuste dos objetivos individuais de estudantes e professores em função de uma estratégia pedagógica que privilegia dialeticamente a construção coletiva do conhecimento e a autonomia". Ele destaca ainda a "importância das pessoas, acima das tecnologias, e da colaboração entre as pessoas para uma avaliação de todos os momentos, inclusive considerando as trajetórias de cada participante", sendo que cada um traz sua trajetória pessoal e os conhecimentos baseados em múltiplas fontes.

Com esse pensamento, que encerra a parte teórica, este estudo parte para a sua concepção metodológica, tendo a etapa empírica apresentada a seguir.

\section{METODOLOGIA}

Para melhor análise sobre as discussões acerca das devolutivas e interação entre alunoprofessor acerca das atividades e avaliações na modalidade do ensino a distância, realizou-se uma pesquisa junto a alunos de todo o Brasil, que cursam a graduação no curso de bacharelado em Administração na modalidade a distância. A pesquisa foi aplicada de forma online, com 
questionário de natureza qualitativa, utilizando a estratégia de estudo de caso como instrumento, em uma instituição privada de ensino superior, localizada no estado de São Paulo. No resgate metodológico sobre o estudo de caso, há controvérsias entre autores com relação ao tipo de pesquisa. Para Godoy (2006), possui a visão positivista, no entanto, é considerado, em seu artigo, somente como método qualitativo de orientação interpretativista. Para Yin (2005), o estudo de caso possui uma visão positivista, de modo a mesclar os dados qualitativos e quantitativos. No entanto, aqui se interpreta como qualitativo pelo fato de ter sido um processo investigativo e interpretativo.

No estudo de caso, o pesquisador pode analisar e compreender, de modo mais preciso, os fenômenos verificados em situações vivenciadas a partir da prática. Além disso, o estudo de caso também pode ser motivado por questões relacionadas à natureza conceitual, ou seja, o pesquisador busca responder a questões sobre '[...] processos ('por que' e 'como' as coisas acontecem), assim como a questões de compreensão que procuram descrever e interpretar 'o que' aconteceu numa determinada situação" (GODOY, 2006, p.127). Para a elaboração do questionário, foi realizada uma discussão com os discentes do curso, a fim de levantar as atividades e avaliações realizadas pelos alunos e, consequentemente, as devolutivas pela plataforma virtual.

Em seguida, o questionário proposto passou por um processo de validação por um grupo de especialistas em ensino a distância. Após este processo, com o questionário validado em seu conteúdo, este foi encaminhado, por meio de mensagem eletrônica, a 512 alunos de um curso de bacharelado em Administração, modalidade a distância, no período de 10 a 16 de junho de 2012, de polos de apoio de diferentes estados do Brasil. Para a realização da pesquisa, foi criado um link de acesso ao questionário criado na plataforma SurveyMonkey. Foram obtidas 182 respostas, mas por razões de dados ausentes, apenas 157 puderam ser devidamente analisadas. 0 instrumento de coleta de dados foi composto por 26 afirmativas relativas baseadas em quatro constructos aplicados na instituição de ensino em estudo: aula-atividade, prova integrada presencial, planejamento semanal e fórum de dúvidas. Todas as afirmativas avaliavam as devolutivas correspondentes ao construto, algumas delas foram inseridas propositalmente para confirmação de algumas informações. No questionário, foram incluídas cinco questões sobre dados pessoais e de caracterização (gênero, estado civil, idade, polo onde estuda e semestre em curso), podendo ser visualizado no Quadro 1. As respostas foram dispostas em escala estilo Likert de quatro opções, variando de discordo totalmente a concordo totalmente, sendo que, para parâmetros de resposta foram atribuídas definições aos conceitos:

- Concordo Levemente: concordo com a afirmativa, porém, possuo algumas restrições.

- Concordo Totalmente: concordo em todos os aspectos com a afirmativa.

- Discordo Totalmente: discorda da afirmativa, porém, sem plena convicção.

- Discordo Levemente: discordo em todos os aspectos com a afirmativa.

Quadro 1 - Instrumento de coleta de dados do estudo proposto 


\begin{tabular}{|c|c|c|}
\hline \multirow{6}{*}{$\begin{array}{c}\text { Construto } 1 \\
\text { Aula Atividade }\end{array}$} & AT01 & As devolutivas das atividades desenvolvidas contribuem para o meu desenvolvimento. \\
\hline & AT02 & As devolutivas permitem uma maior interação com o meu professor. \\
\hline & AT03 & Receber um retorno sobre minhas atividades me faz sentir importante. \\
\hline & AT04 & As devolutivas das atividades não contribuem para o meu aprendizado. \\
\hline & AT05 & Em minha opinião, as devolutivas de atividades não contribuem para o meu conhecimento. \\
\hline & AT06 & Gosto da forma que as devolutivas das atividades são apresentadas. \\
\hline \multirow{7}{*}{$\begin{array}{c}\text { Construto } 2 \\
\text { Prova Integrada } \\
\end{array}$} & PI01 & A forma como as devolutivas das provas são feitas contribuem para o meu aprendizado. \\
\hline & $\mathrm{PI02}$ & Meu desenvolvimento também é influenciado pelo retorno que recebo sobre minhas avaliações. \\
\hline & $\mathrm{PI03}$ & Prefiro as devolutivas de provas ao vivo em teleaula. \\
\hline & $\mathrm{PI04}$ & Prefiro as devolutivas de provas apenas escritas. \\
\hline & PI05 & Em minha opinião, as devolutivas das provas não contribuem para o meu conhecimento. \\
\hline & PI06 & Receber um retorno sobre minhas provas me faz sentir importante. \\
\hline & $\mathrm{PI07}$ & Gosto da forma que as devolutivas das provas são apresentadas. \\
\hline \multirow{7}{*}{$\begin{array}{c}\text { Construto } 3 \\
\text { Planejamento } \\
\text { Semanal }\end{array}$} & PS01 & Sempre desenvolvo as atividades previstas no planejamento semanal. \\
\hline & PS02 & O planejamento semanal me auxilia a entender melhor os temas tratados em teleaula. \\
\hline & PS03 & O planejamento semanal não contribui para o meu desenvolvimento. \\
\hline & PS04 & Quase nunca desenvolvo as atividades propostas no planejamento semanal. \\
\hline & PS05 & Sinto maior interação com o professor quando desenvolvo as atividades do planejamento semanal. \\
\hline & PS06 & As devolutivas das atividades desenvolvidas no planejamento semanal são importantes. \\
\hline & PS07 & Não gosto da forma das devolutivas das atividades do planejamento semanal. \\
\hline \multirow{6}{*}{$\begin{array}{c}\text { Construto } 4 \\
\text { Fórum de dúvidas } \\
\end{array}$} & FO01 & O fórum de dúvidas é uma ótima ferramenta para sanar minhas dúvidas com o professor. \\
\hline & FO02 & Sempre utilizo o fórum para sanar dúvidas sobre temas tratados em teleaula. \\
\hline & FO03 & Através do fórum de dúvidas tenho maior proximidade com o professor. \\
\hline & FO04 & O fórum de dúvidas auxilia no meu desenvolvimento. \\
\hline & FO05 & Gosto da forma com que os professores respondem as minhas dúvidas no fórum. \\
\hline & FO06 & Sinto-me importante ao receber um retorno do professor sobre minhas dúvidas no fórum. \\
\hline \multirow[b]{5}{*}{ Dados Pessoais } & GEN & Gênero \\
\hline & ESTC & Estado Civil \\
\hline & IDA & Idade \\
\hline & SEM & Semestre \\
\hline & POLO & Polo \\
\hline
\end{tabular}

Fonte: Elaborado pelos autores.

\section{RESULTADOS E DISCUSSÃO}

Nesta seção também se apresenta a IES privada escolhida para o estudo de caso objeto desta investigação. Ela é uma instituição privada de ensino superior localizada no município de São Bernardo do Campo, estado de São Paulo (SP). Sua história teve início em 1938 e atualmente possui três campi nessa cidade, onde são distribuídos os cursos de graduação (modalidade presencial e ensino a distância [25 polos] - nas áreas Biológicas e Saúde, Comunicação, Humanidades, Gestão e Negócios e Tecnologia).Possui também o programa de pós-graduação stricto sensu em Administração, Ciências da Religião, Comunicação Social, Educação, Odontologia e Psicologia da Saúde, além dos cursos de especialização (modalidade presencial e ensino a distância) lato sensu.

Para a amostra total de alunos respondentes, obteve-se um total de 157 respostas. Desse total, $58 \%$ são mulheres, idade média de 33 anos, $22 \%$ do polo de Mauá (SP), $18 \%$ de São José dos Campos (SP), 8\% de Macaé (Rio de Janeiro). Sendo que os percentuais restantes estavam distribuídos por mais 22 diferentes polos no Brasil. Em relação ao estado civil, $58 \%$ são casados, $31 \%$ solteiros e os demais declaram outras condições matrimoniais (11\%). A seguir estão analisados os pontos mais relevantes de cada um dos constructos avaliados.

Analisando-se o construto Aula-atividade, $96 \%$ dos respondentes concordam que as devolutivas das atividades contribuem para o seu desenvolvimento. Além dos alunos concordarem em receber a devolutiva de suas atividades desenvolvidas no polo de apoio presencial, $83 \%$ deles 
acreditam que a devolutiva permite maior interação com o seu professor e $94 \%$ sentem-se importante quando recebem tal retorno das atividades.

Dentre os respondentes, $77 \%$ aprovam o atual modelo de devolutiva feito hoje na instituição pesquisada. O modelo é dado a cada atividade entregue pela plataforma moodle, utilizada por esta instituição e por outras que possuem a modalidade do ensino a distância.A plataforma moodleé um software livre e é utilizada como o Ambiente Virtual de Aprendizagem (AVA) nas universidades que oferecem os cursos online para a interação e contato com os alunos. Este resultado demonstra que algumas instituições já estão de encontro com a dialocidade e com a superação da concepção bancária, defendida por Freire (1987).

$\mathrm{Na}$ análise do construto da Prova Integrada, podemos identificar que $68 \%$ dos respondentes afirmam veemente que o seu desenvolvimento também é influenciado pelo retorno que recebe das avaliações integradas presenciais e $26 \%$ concordam levemente com este ponto.

Com relação à forma da devolutiva, $76 \%$ aprovam recebê-la através da tele aula ao vivo, mas do mesmo universo total pesquisado,52\% preferem que a devolutiva seja apenas escrita. Atualmente, a instituição pesquisada utiliza a forma de devolutiva ao vivo, onde todos os professores temáticos, que correspondem às disciplinas aplicadas, participam da tele aula explanando cada uma das questões elaboradas e as respostas esperadas em cada uma delas.

Com relação ao planejamento semanal, os respondentes informam que $97 \%$ sempre desenvolvem as atividades do planejamento semanal. Na instituição pesquisada, nem sempre há entrega dessas atividades, ela ocorre vinculada ao cronograma estabelecido para o semestre. Contanto, mesmo não havendo a entrega regular, os alunos informam desenvolverem tais atividades. $O$ alunado também afirma que as atividades do planejamento semanal os auxilia no entendimento dos temas propostos em tele aula, $96 \%$ concordaram com a afirmativa.

Sobre o construto Fórum de Dúvidas, $90 \%$ dos respondentes opinam que a ferramenta é uma ótima forma de sanar possíveis dúvidas, e $79 \%$ do universo total, afirmam que através do fórum de dúvidas sentem maior proximidade com o professor. O fórum é uma ferramenta disponibilizada pela instituição pesquisada a todos os envolvidos, através dela é possível que os alunos façam perguntas e comentários, e o professor temático que ministrou a tele aula da semana, respondam as questões, interagindo diretamente com os alunos.

\section{CONCLUSÃO}

Ao se analisar os resultados da pesquisa, foi possível identificar que a importância da devolutiva é confirmada e evidenciada pelos respondentes e que a instituição estudada, que adota esta forma de conduzir o ensino no modelo a distância, está de acordo com a perspectiva do alunado. Em princípio, trata-se de resultado positivo, pois ratifica a posição de superação da concepção bancária (FREIRE, 1996) na educação da modalidade a distância, usando-se os resultados do estudo em particular e que podem ser expandidos para as demais IES com atuação similar. Esta é a principal contribuição deste estudo, uma vez que apresenta importantes aspectos para ampliação da discussão sobre o tema: avaliação assumida como elemento de formação do estudante, e não apenas instrumento classificatório; devolutiva na função primordial de ensino, e não enquanto mera divulgação de performance acadêmica. Ou seja, amplia-se o espectro da aula para uma real dimensão do ensino, como sugere Demo (2003). 
Para o aluno, receber o retorno de suas atividades e avaliações o faz sentir importante e, sobretudo, o faz perceber que há uma troca de conhecimentos, além do fato de que tal prática pedagógica amplia a dimensão do ensino. Neste momento, a identificação das vertentes DAR, Democratização (D), a Autonomia do aluno (A) e a Relação professor-aluno menos hierarquizada $(R)$, fica mais clara e visível diante dos resultados obtidos.

Na pesquisa aplicada na IES, percebeu-se que os respondentes de 25 diferentes polos no Brasil, confirmam a questão da democratização no ensino a distância. Identificou-se a autonomia quando se interpretou a responsabilidade que aluno transparece nas respostas apontadas. 0 alunado sabe da importância que os instrumentos e ferramentas disponíveis têm no desenvolvimento de seus estudos. E a relação professor-aluno também é confirmada na pesquisa, em que o indivíduo é a favor desta interação e a maioria dos respondentes confirma tal existência. Ou seja, no contexto da EaD, não somente a eficiência das ferramentas tecnológicas deve entrar em cena, como registram Quintana e Quintana (2012), mas a gestão acadêmica de cursos em tal modalidade deve partir de premissas que demandem comprometimento docente na relação com alunos distribuídos por diversas regiões do país (com suas perspectivas de ensino próprias, além de outras peculiaridades de ordem cultural), uma vez que o mero depósito de material (por melhor que seja sua elaboração) não se configura como prática de ensino.

Reconhece-se, portanto, que a atuação docente, no cenário da EaD, implica preparo de material e envolvimento docente em busca da percepção discente a respeito do compromisso com atividades acadêmicas sob sua relativa responsabilidade (a questão da "distância docente"). Tal demanda, naturalmente depende da qualidade das ferramentas tecnológicas disponíveis, mas o principal aspecto é a provocação, a partir do professor, em relação à importância da realização das atividades acadêmicas estipuladas. Elementos semelhantes foram discutidos no trabalho de Silva e Rocha (2012). No caso deste artigo, destacou-se a percepção dos estudantes no tocante a elementos como aula atividade, prova integrada, planejamento semanal e fórum de dúvidas.

Sugere-se, para futuros estudos, verificar se há uma discrepância nas práticas de avaliação online em relação ao que está regulamentado pela legislação educacional brasileira, bem como similaridades nos instrumentos utilizados nos cursos presenciais em relação à modalidade EaD, a partir da visão dos docentes. Outra sugestão para novas investigações pode ter lugar também em outros tipos de atividades acadêmicas, em adição às que foram aqui discutidas, afinal, a dinâmica da gestão acadêmica na EaD sempre terá novos aspectos para reflexão.

\section{REFERÊNCIAS}

1. ALMEIDA, L.; MARINHO-ARAUJO, C. M.; AMARAL, A.; DIAS, D. Democratização do acesso e do sucesso no ensino superior: uma reflexão a partir das realidades de Portugal e do Brasil. Avaliação, v. 17, n. 3, p. 899-920, nov 2012.

2. ARIEIRA, J. O.; DIAS-ARIEIRA, C. R.; FUSCO, J. P. A.; SACOMANO, J. B.; BETTEGA, M. O. DE P. Avaliação do aprendizado via educação a distância: a visão dos discentes. Ensaio: aval. pol. públ. Educ., v. 17, n. 63, p. 313-340, 2009.

3. BELUCE, A. C.; OLIVEIRA, K. L. As estratégias de ensino e de aprendizagem em condições de ensino online. Hipertextus, n. 9, p. 1-16, dez 2012.

4. BENFATTI, E. F. S. S.; STANO, R. C. M. T. Utilização da tecnologia em Educação a Distância na 
formação de engenheiros de produção da Universidade Federal de Itajubá: uma avaliação educacional. Gest. Prod., v. 17, n. 2, p. 433-446, 2010.

5. BERTOLIN, J. C. G.; DE MARCHI, A. C. B. Instrumentos para avaliar disciplinas da modalidade semipresencial: uma proposta baseada em sistemas de indicadores. Avaliação, v. 15, n. 3, p. 131-146, nov 2010.

6. BRASIL. Ministério da Educação (MEC). Instituto Nacional de Estudos e Pesquisas Educacionais Anísio Teixeira (INEP). Resumo Técnico: Censo da Educação Superior 2009. Brasília: INEP, 2010. Disponível em: <http://www.inep.gov.br> Acesso em: 10 mar. 2011.

7. BRASIL. Portal MEC. Ministério da Educação. Legislação de educação a distância.2007. Disponível em: <http://portal.mec.gov.br/index.php>. Acesso em: 05 jun. 2011.

8. BRAUER, M.; ALBERTIN, A. L. Resistência à Educação a Distância na Educação Corporativa . Encontro da ANPAD - EnANPAD, 34. Anais... Rio de Janeiro (RJ): ANPAD, set 2010.

9. CALDAS, C. B.; SOMENSARI, P.; COSTA, S. N.; SIQUEIRA, M. M. M.; CLARO, J. A. C. S. Satisfação e Engajamento no Trabalho Entre Docentes Temáticos e Auxiliares do Ensino à Distância (EAD) de Uma Universidade Privada Brasileira. Simpósio de Pesquisa e Ensino em Administração SimPEAD, 1. Anais... São Paulo (SP): PUC-SP, 2012.

10. CARVALHO, M. C.; SILVA, F. M.; COSTA, C. F.; RHODEN, M. I. S. Aprendizagem Organizacional a partir das Práticas de Educação a Distância da EA/UFRGS. Encontro da ANPAD - EnANPAD, 34. Anais... Rio de Janeiro (RJ): ANPAD, set 2010.

11. CARVALHO, R. S.; ABBAD, G. Avaliação de Treinamento a Distância: Reação, Suporte à Transferência e Impactos no Trabalho. RAC - Revista de Administração Contemporânea, v. 10, n. 1, p. 95-116, 2006.

12. CAVALCANTI JÚNIOR, H. S. B.; FERRAZ, I. N. Uma análise da pesquisa sobre educação a distância nos periódicos brasileiros de Administração (2002-2011). Gestão \& Regionalidade, v. 29, n. 85, p. 93-104, 2013.

13. CLEMENTINO, A.; AJOURI, Y. R.; SOUZA, D. B.; FERNANDES, W. S.; DUTRA, S. R. A Educação a Distância no Ensino Superior Brasileiro: Uma Visão Geral. Revista Científica Hermes, v. 6, p. 615, 2012.

14. DEMO, P. Aula não é necessariamente aprendizagem. Revista Ensaio (CESGRANRIO), n. 43, p. 1-22, 2003.

15. FÉLIX. Efeitos da burocracia na avaliação da Educação Superior. Holos, ano 29, v. 6, p. 132148, 2013.

16. FREIRE, P.. Pedagogia da Autonomia: Saberes necessários à prática educativa. 33 ed. Rio de Janeiro: Paz e Terra, 1996.

17. FREIRE, P.. Pedagogia do Oprimido. 17 ed. Rio de Janeiro: Paz e Terra, 1987.

18. FREITAS, C. C. R. A função social do professor: concepções em conflito. Trabalho Necessário, v. 10, n. 15, p. 1-20, 2012.

19. FROTA, G. B.; TEODÓSIO, A. S. S. Profissão docente, profissão decente?: Estratégias de professores frente ao sofrimento no trabalho em um ambiente de inovação pedagógica. Encontro da ANPAD - EnANPAD, 36. Anais... Rio de Janeiro (RJ): ANPAD, set 2012

20. GHEDINE, T.; TESTA, M. G.; FREITAS, H. M. R. DE. Educação a distância via internet em grandes 
empresas brasileiras. RAE-revista de administração de empresas, v. 48, n. 4, p. 49-63, 2008.

21. GODOY, A.S. Estudo de caso qualitativo. In: GODOI, C. K.; BANDEIRA-DE-MELLO, R.; SILVA, A. B. D.. Pesquisa Qualitativa em Estudos Organizacionais: Paradigmas, Estratégias e Métodos. 1. ed. São Paulo: Saraiva, 2006, cap. 4, p. 115-145.

22. GOMES, L. F. EAD no Brasil: Perspectivas e Desafios. Avaliação, v. 18, n. 1, p. 13-22, mar 2013.

23. JEANNOT, F.; JOLIBERT, A. La distance temporelle, la simulation mentaleet le processusd'adoptiond'innovationstechnologiques complexes. Rechercheet Applications en Marketing, v. 28, n. 1, p. 70-91, 11 abr 2013.

24. KEYS, B.; WOLFE, J. The Role of Management Games and Simulations in Education and Research. Journal of Management, v. 16, n. 2, p. 307-336, 1990.

25. KLERING, L. R.; SCHRÖEDER, C. DA S. Desenvolvimento de um Ambiente Virtual de Aprendizagem à luz do Enfoque Sistêmico. TAC - Tecnologia em Administração e Contabilidade, v. 1, n. 2, p. 42-54, 2011.

26. LAGUARDIA, J.; PORTELA, M. C.; VASCONCELLOS, M. M. Avaliação em ambientes virtuais de aprendizagem. Educação e Pesquisa, v. 33, n. 3, p. 513-530, 2007.

27. LANDIM, C. M. M. P. F. Educação à distância: algumas considerações. Rio de Janeiro: Editora UFRJ, 1997.

28. LEITE, D.; LEITE, M. C. L.; GENRO, M. E. H. et al. Avaliação participativa online e off-line. Avaliação: Revista da Avaliação da Educação Superior (Campinas), v. 12, n. 3, p. 445-460, set 2007.

29. LIMA, M. V. A. DE; SOARES, T. C.; DELBEI, L. H. H.; BACKER, C. C. Fatores Críticos de Sucesso na Educação Superior Brasileira. Revista Gestão Universitária na América Latina - GUAL, v. 5, n. 3, p. 245-263, dez 2012.

30. MALULEQUE, C.; COSTA, N. Avaliação online das Aprendizagens na Licenciatura em Gestão de Negócios na Universidade Eduardo Mondlane (Moçambique): do diagnóstico da situação à apresentação de uma proposta de intervenção. Indagatio Didactica, v. 4, n. 4, p. 62-84, dez 2012.

31. MARQUES, M. C. S.; EGRY, E. Y.; SILVA, M. B. et al.Tele-education and Competencies Assessment to Brazilian's auxiliary nurse. Ver Esc Enferm USP, v. 41, n. Esp, p. 841-846, 2007.

32. MARTINELLI, D. P.. A Utilização de Jogos de Empresas no Ensino da Administração, Dissertação (Mestrado em Administração) - Faculdade de Economia, Administração e Contabilidade. Universidade de São Paulo. São Paulo. 1987. 262 p.

33. MATTOS, A. C. Empregos e empresas que mudarão com a internet. RAE-revista de administração de empresas, v. 39, n. 3, p. 73-108, 1999.

34. MONDADORI, M. G.; SCHRÖEDER, C. S.; RUAS, R. L. Contribuições Teórico-Empíricas para a Avaliação Formativa em Comunidades Virtuais de Aprendizagem: o Caso de um Curso de Graduação em Administração a Distância. Encontro da ANPAD - EnANPAD, 32. Anais... Rio de Janeiro (RJ): ANPAD, set. 2008.

35. NOVAIS, S. M.; FERNANDES, A. S.. A Institucionalização do ensino a distância no Brasil: um o caso da graduação em administração na Universidade Federal do Rio Grande do Norte. Revista de Ciências da Administração, v. 13, n. 29, p. 152-172, jan. /abr. 2011. 
36. OLIVEIRA, G. P. DE. Estratégias multidimensionais para a avaliação da aprendizagem em cursos on-line. Ensaio: aval. pol. públ. Educ., v. 18, n. 66, p. 105-138, 2010.

37. PEdRosA, S. M. P. A.; MAMEde-NEVES, M. A. C. O "Jovem ProUni" e as tecnologias de informação e comunicação. R. bras. Est. pedag., v. 93, n. 233, p. 135-146, 2012.

38. QUINTANA, A. C.; QUINTANA, C. G. A execução das tarefas virtuais no contexto da educação a distância: um estudo em um curso de graduação em administração. Revista Gestão Universitária na América Latina - GUAL, v. 5, n. 2, p. 277-297, ago 2012.

39. RAUSCH, R. B.; SILVA, M. Z.;THEISS, V. Avaliação Formativa no Processo Ensino e Aprendizagem na Educação Superior: Um Estudo de Caso Realizado na Disciplina de Matemática Financeira. Encontro da ANPAD - EnANPAD, 36. Anais... Rio de Janeiro (RJ): ANPAD, set 2012.

40. RIVARD, S.; LAPOINTE, L. A multilevel model of resistance to information technology implementation. MIS Quarterly, v. 29, n. 3, p. 461-469, 2005.

41. ROSA, M.; MALTEMPI, M. V. A avaliação vista sob o aspecto da educação a distância. Ensaio: aval. pol. públ. Educ., v. 14, n. 50, p. 57-76, 2006.

42. SANTOS, J. F. S.. Avaliação no Ensino à Distância. Revista Ibera Americana de Educação, v. 38, n. 4, 2006.

43. SAUAIA, A. C. A.. Laboratório de Gestão: Simulador, Jogo de Empresas e Pesquisa Aplicada. Barueri, SP: Manole, 2008.

44. SAWITZKI, R. C.; LORENZETTI, J. V.; GRIZA, A.; OLIVEIRA, L. Y. M.. Sentido, significado do trabalho e identidade nas atividades de tutoria em educação a distância. Encontro da ANPAD - EnANPAD, 36. Anais... Rio de Janeiro (RJ): ANPAD, set 2012.

45. SEGENREICH, S. C. D. Desafios da educação à distância ao sistema de educação superior : novas reflexões sobre o papel da avaliação. Educar UFPR, n. 28, p. 161-177, 2006.

46. SCHROEDER, C. S. Educação a Distância e mudança organizacional na Escola de Administração da UFRGS: Uma teoria substantiva. 2009. 252 f. Tese de Doutorado em Administração. Programa de Pós-Graduação em Administração. Porto Alegre (RS): Universidade Federal do Rio Grande do Sul, 2009.

47. SILVA, Â. C.; SILVA, C. M. T. Do diagnóstico às questões avaliativas: um caminho possível via prática de avaliação em educação a distância. Ensaio: Avaliação e Políticas Públicas em Educação, v. 17, n. 63, p. 293-312, jun. 2009.

48. SILVA, J. A. R.; ROCHA, E. C. M. Gestão Acadêmica de Cursos de Graduação em Administração: Comparação entre um curso presencial e outro a distância. Revista Gestão Universitária na América Latina - GUAL, v. 5, n. 4, Edição Especial, p. 153-171, 2012.

49. SOUZA, R. P.; MOITA, F. M. C. S. C.; CARVALHO, A. B. G. (Orgs.). Tecnologias Digitais na Educação. Campina Grande (PG): EDUEPB, 2011. 276 p.

50. SOUZA-SILVA, J. C. DE; DAVEL, E. Da ação à colaboração reflexiva em comunidades de prática. RAE-revista de administração de empresas, v. 47, n. 3, p. 53-65, 2007.

51. TAKAHASHI, T. (Org.). Sociedade da Informação no Brasil: Livro Verde. Brasília (DF): Ministério da Ciência e Tecnologia, 2000. 195 p.

52. TEIXEIRA, J. A.; ISIDRO FILHO, A. Educação a Distância na Perspectiva da Inovação em Serviços. Encontro da ANPAD - EnANPAD, 36. Anais... Rio de Janeiro (RJ): ANPAD, set 2012. 
53. TEZZA, M. M. Aceitação e Resistência à Educação a Distância: Um Estudo em uma Empresa do Setor Metalúrgico. Encontro da ANPAD - EnANPAD, 36. Anais... Rio de Janeiro (RJ): ANPAD, set 2012.

54. VEIGA, I. P. A.. Projeto Político-pedagógico da escola: uma construção coletiva. In: VEIGA, I. P. A. (Org.). Projeto político-pedagógico da escola: uma construção possível. 17 ed. São Paulo: Papirus, 2004, p. 11-36.

55. VIEIRA, E. M. F.; SANTOS, N. Gestão estratégica do conhecimento no campo da avaliação em educação a distância. Cadernos, v. III, n. 4, p. 1-7, dez 2005.

56. YIN, R. K. Estudo de Caso: Planejamento e Método. 3a Ed. Porto Alegre: Bookman, 2005.

57. ZERBINI, T.; ABBAD, G. S. Reação aos procedimentos instrucionais de um curso via internet: validação de uma escala. Estudos de Psicologia, v. 26, n. 3, p. 363-371, 2009. 